\title{
A DESIGN AND DEVELOPMENT OF HSURMSA FOR GPS, WLAN AND WIMAX COMMUNICATION APPLICATION
}

\author{
Rajeshwari Biradar ${ }^{1}$, S.N.Mulgi ${ }^{2}$ \\ ${ }^{I}$ Research student, Department of PG Studies and Research in Applied Electronics, Gulbarga University, \\ Kalaburagi-585106, Karnataka, INDIA \\ rajeshwarigbr@gmail.com, \\ ${ }^{2}$ Professor, Department of PG Studies and Research in Applied Electronics, Gulbarga University, \\ Kalaburagi-585106, Karnataka, INDIA \\ s.mulgi@rediffmail.com
}

\begin{abstract}
In this paper,the design of hybrid semi-circular U-slot loaded rectangular microstrip antenna (HSURMSA) designing for dualwideband operation is presented. The antenna is printed on a low-cost FR-4 substrate. The proposed antenna covers 1.224 to $4.8918 \mathrm{GHz}$, which covers forGPS (1.6GHz), WiMAX (3.5/5.5 GHz) and WLAN (2.4/5.2/5.8 GHz) operating bands respectively. This antenna is developed from the combination of both rectangular and circular radiating patch overlapped together and results into a hybrid U-shape model. The proposed antenna has a compact size of $40 \times 60 \times 1.6 \mathrm{~mm} 3$ including partial truncated ground plane on the bottom side of the dielectric material. The obtained dual-band operation of the antenna is mainly controlled by the dimension of $U$-shape slot etched at Centre of the radiating patch. The comparisons of simulated and measured results are discussed in this paper and the simulated result shows a good agreement with measured one.
\end{abstract}

Keywords: Hybrid Semi-Circular U-Slot Dual-Band, GPS, WLAN And Wimax.

$* * *$

\section{INTRODUCTION}

The design and development of the antenna capable to operate for single, dual, triple and multiband application has increased in usage of portable wireless communication systems. However, the development of antenna with dualband or multiband operation is not only beingenough which also intending towards a simple physical configuration and must be a compact in its size, les weight and easy fabrication and integrated with a MMIC circuits. The WLAN (Wireless Local Area Networks)and WiMAX (Worldwide Interoperability for Microwave Access)systems, which generally covers a $2.4,5.2 / 5.8 \mathrm{GHz}$ and $3.5 / 5.5$ are Usually designed for short-range wireless communication systems designated by IEEE $802.11 \mathrm{a} / \mathrm{b} / \mathrm{c} / \mathrm{n}$ standards. Also the WiMAX has newly started for mobile broad-band,a wireless service which issupported by the IEEE .16e standards [1-6]. Presently, these WLAN and WiMAX communication services are becomes a most popular research area ofinterest in antenna developments. However, merging these two services into a single system, it is necessary of a single antenna needs to cover thebothoperating bands. Hence, the demand of a single antenna with compact size to covers the both dual band properties such as WLAN and WiMAX is increasing in various short and long range applications in wireless communication systems[7-11].

In this paper, we proposed a dual wide band hybrid type microstrip antenna with a U-slot for WiMAX and WLAN applications.Byinserting a U-slot at the middle of the radiating patch the wide dual bands are achieved which covers the GPS (1.6 GHz), WiMAX $(3.5 / 5.5 \mathrm{GHz})$ and WLAN $(2.4 / 5.2 / 5.8 \mathrm{GHz})$ respectively. The proposed antenna is successfully optimized by using HFSS tool. The obtained simulated results are further compared with the measured one. Both measured and simulated results are agreed with each other. The proposed antenna gives dual operating bands with $-10 \mathrm{~dB}$ impedance bandwidth of $38.94 \%$ (1.224- $1.81 \mathrm{GHz})$ and $70.79 \%(2.336-4.891 \mathrm{GHz})$. Details of the proposed antenna and theircorresponding results are presented and discussed in this paper.

\section{ANTENNA DESIGN}

The geometry of proposed HSURMSA along with its dimension is shown in Figure1. The geometrical parameters of the proposed antenna were obtained by using Ansoft high-frequency structure simulator (HFSS). The antenna is printed on a FR-4 substrate with dielectric constant of 4.2, thickness of $1.6 \mathrm{~mm}$ and loss tangent $(\tan \delta)$ is 0.02 . This antenna structure is named as hybrid because the rectangular and circular geometry are combined together. The U- slot inserted on the patch. The proposed antenna is excited by a simple $50 \Omega$ microstripline feed having width $\mathrm{W}_{\mathrm{f}}=0.317 \mathrm{~mm}$ and length $\mathrm{L}_{\mathrm{f}}=2.4 \mathrm{~mm}$. At the bottom side of the ground plane a partially truncated ground plane is etched which is slightly below the radiating patch to get desired operating bands. The offset gap $\mathrm{d}$ is $0.5 \mathrm{~mm}$ between the radiating patch and bottom ground plane. Final designed values of the antenna parameters are specified in Table. I. 


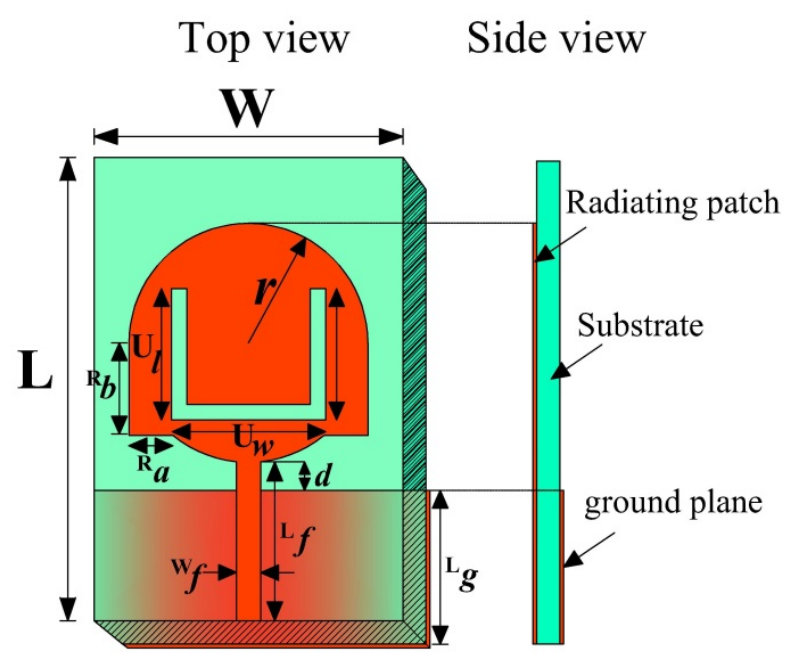

Fig. 1Geometry of HSURMSA

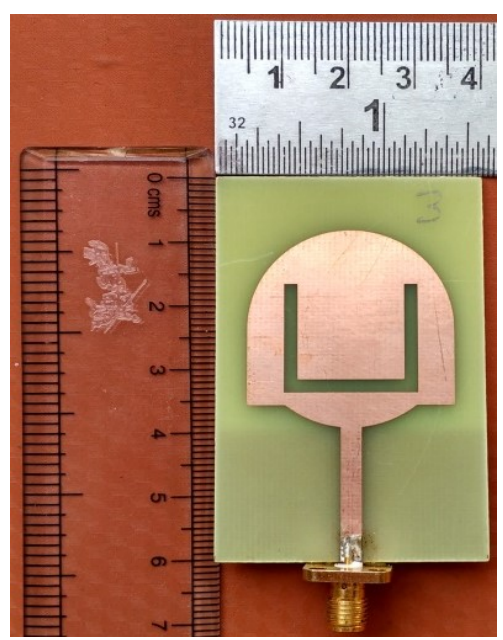

(a)

Top view

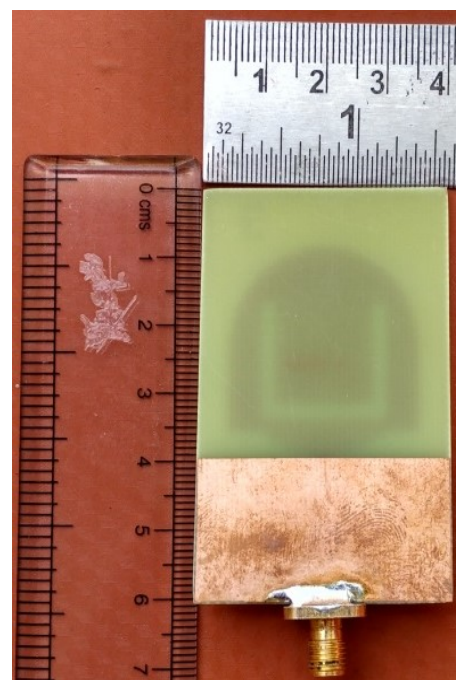

(b) bottom view

Fig. 2Photographs of HSURMSA

The top and bottom view of HSURMSA is as shown in Figure 2 (a) and 2 (b) respectively. The antenna parameters are measured experimentally by using network analyzer.
Table: I Antenna Parameters

\begin{tabular}{|l|l|}
\hline Parameters & Dimensions in $\mathbf{~ m m}$ \\
\hline $\mathrm{W}$ & 40 \\
\hline $\mathrm{L}$ & 60 \\
\hline $\mathrm{U}_{\mathrm{l}}$ & 1.2 \\
\hline $\mathrm{U}_{\mathrm{w}}$ & 0.568 \\
\hline $\mathrm{R}_{\mathrm{b}}$ & 07 \\
\hline $\mathrm{R}_{\mathrm{a}}$ & 1.94 \\
\hline $\mathrm{W}_{\mathrm{f}}$ & 0.317 \\
\hline $\mathrm{L}_{\mathrm{f}}$ & 2.4 \\
\hline $\mathrm{L}_{\mathrm{g}}$ & 1.9 \\
\hline$d$ & 0.5 \\
\hline$r$ & 1.55 \\
\hline
\end{tabular}

\section{RESULTS AND DISCUSSION}

Figure 3 shows the measured and simulated return loss plot of the proposed antenna HSURMSA. From this figure it is observed that, there are two resonant frequencies are resonates at center frequencies of 1.6 and $3.81 \mathrm{GHz}$. The proposed antenna exhibits dual-wide-band characteristics. The experimental impedance bandwidth for the first operating frequency band is from $1.22-1.81 \mathrm{GHz}$ which is $38.94 \%$ and for second band from $2.33-4.89 \mathrm{GHz}$ which is $70.79 \%$. These two operating bands are covering the GPS $(1.6 \mathrm{GHz})$ WIMAX $(3.5 / 5.5 \mathrm{GHz})$ and WLAN (2.4/5.2/5.8 $\mathrm{GHz}$ )wireless services. There is a good agreement is considered between the simulation and measured results.

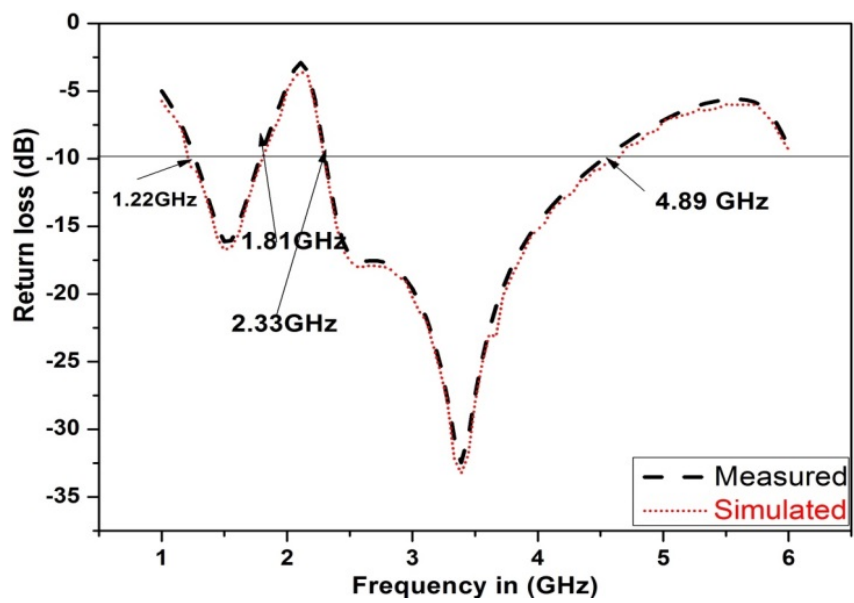

Fig.3 Variations of return loss versus frequency of HSURMSA

To illustrate the resonance mechanisms for the proposed antenna, the simulated current distribution at two resonant frequencies 1.6, and 3.89 GHz are illustrated in Figure 4 (a) and (b) respectively. Current distribution in Figure 4. (a) appear at feed line and in Figure 4. (b) It appears on bottom surface of the radiating patch and feed line which indicates that the antenna is operating for dual-wideband of frequencies. 

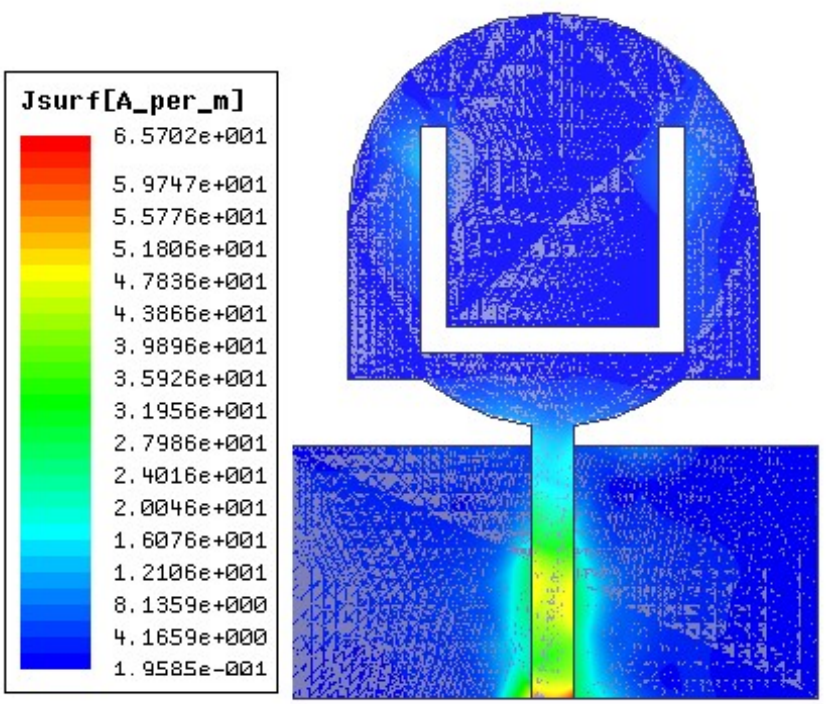

(a)

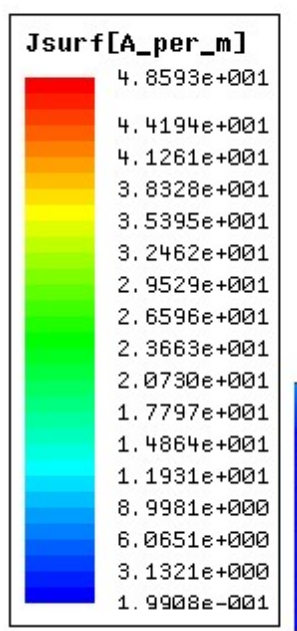

(b)

Fig. 4 Current distributions of HSURMSA observed at (a) $1.6 \mathrm{GHz}$, (b) $3.81 \mathrm{GHz}$

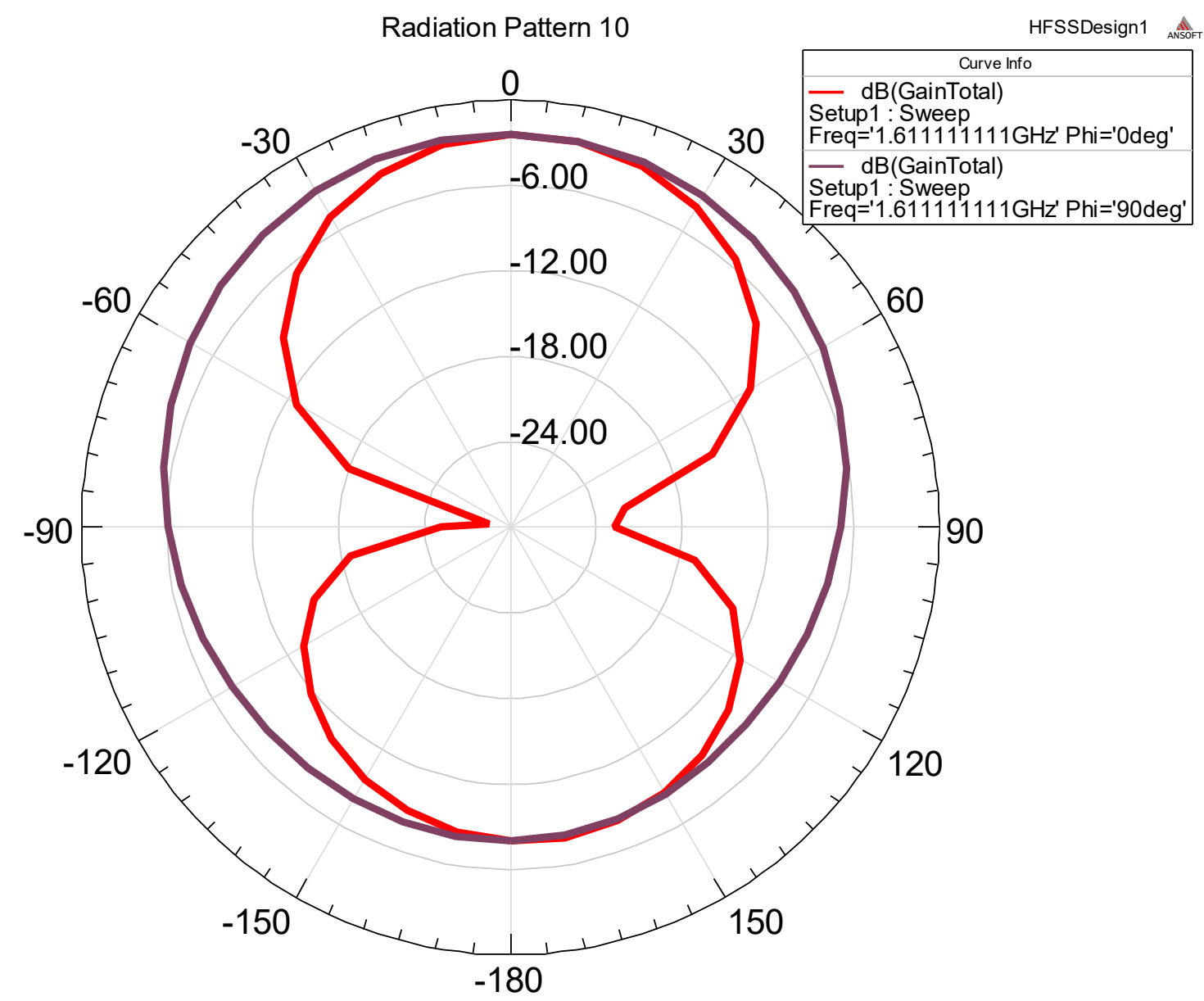

(a) 


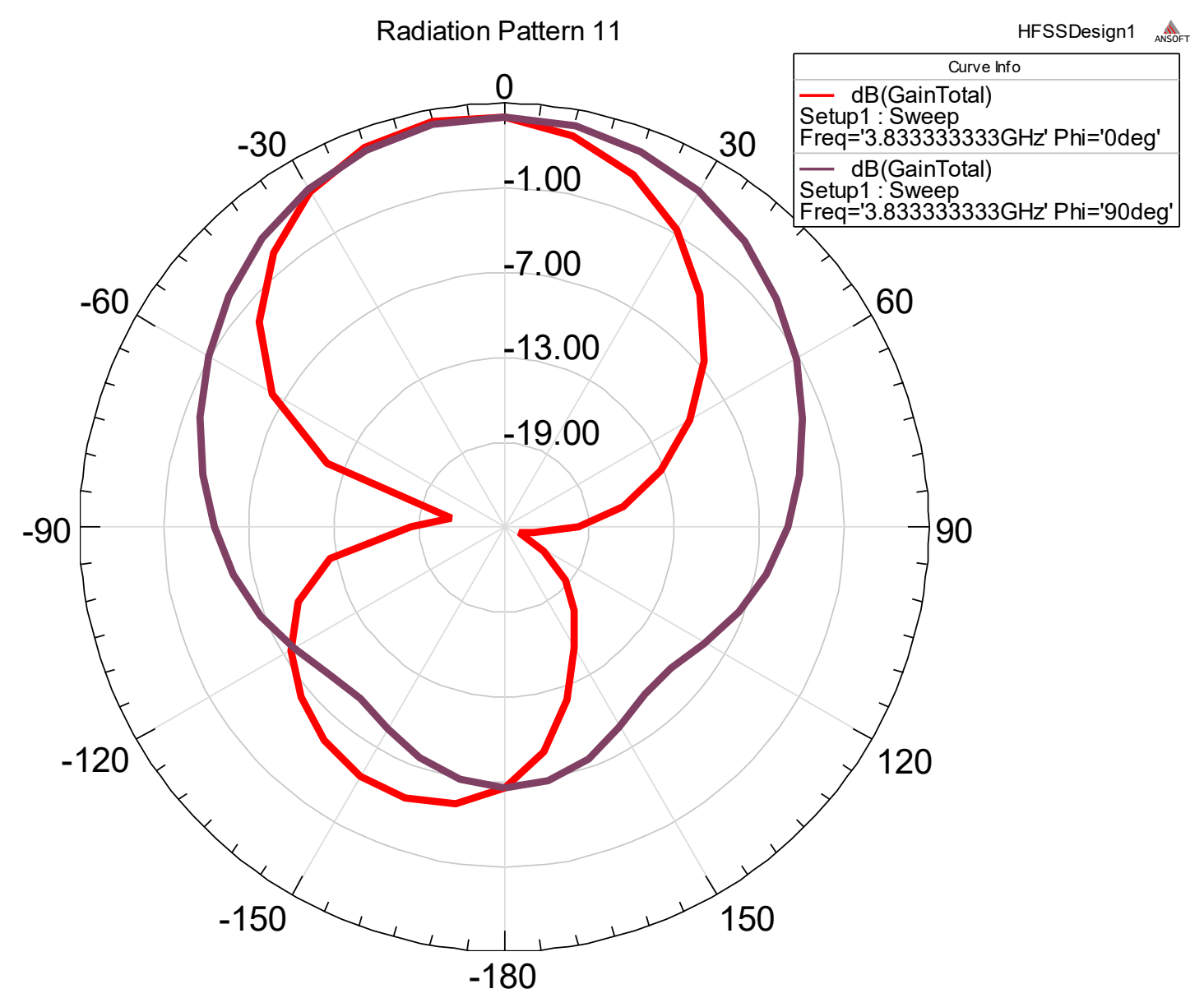

(b)

Fig. 5 Radiation pattern of HSURMSA observed at (a) $1.6 \mathrm{GHz}$, (b) $3.81 \mathrm{GHz}$

\section{CONCLUSION}

A novel design of HSURMSA has been designed successfully for dual-wide band operations which cover GPS, WLAN and WiMAX applications. The structure of antenna is hybrid in nature and having slot inside it. By suitably varying the structure and dimension of the slot the designed radiation requirement is possible from this study. The $-10 \mathrm{~dB}$ bandwidth of the proposed antenna is $38.94 \%$ for the first frequency band and $70.79 \%$ for the second frequency band. The proposed HSURMSA antenna is compact in its physical configuration and is manufactured on low cost FR4 substrate which is fed by a simple $50 \Omega$ microstrip line feed. The antenna also shows a good broad side linearly polarized and bidirectional radiation pattern. The measured results are compared with the simulated one they shows a good agreement with each other.

\section{ACKNOWLEDGMENT}

The authors are very much thank full to The Dept. of Science and Tech. (DST), Govt. of India, New Delhifor sanctioning the Vector Network Analyzer (VNA) under the FIST Project to the Department of Applied Electronics, Gulbarga University, Kalaburagi.

\section{REFERENCES}

[1]. S. Chaimool and K.L. Chung, CPW-fed mirrored-L monopole antenna with distinct triple bands for Wi-Fi and WiMAX applications, Electron Lett 45 (2009), 928-929.

[2]. C.Y. Pan, C.H. Huang, and T.S. Horng, A new printed G-shaped Monopole antenna for dual band WLAN applications, Microwave Opt Techno Lett 50 (2005), 295-297.

[3]. H. Ma, Q.X. Chu, and Q. Zhang, Compact dual band printed Monopole antenna for WLAN operation, Electron Lett 44 (2008), 834-835.

[4]. I.-F. Chen and C.-M. Peng, Microstrip-fed dual-Ushaped printed Monopole antenna for dual-band wireless communication applications, Electron Lett 39 (2003), 955-956.

[5]. H.F. AbuTarboush, H.-S. Al-Rawhide, and R. Nilavlan, Triple-band double U-slots patch antenna for WiMAX mobile applications, 2008 14th Asia-Pacific Conference on Communication (2008).

[6]. S.Y. Lee and C.C. Yu, A novel wideband asymmetric hybrid antenna for WLAN/Wi-MAX applications, Microwave Opt Techno Lett 51 (2009), 1055-1057.

[7]. C.Y. Pan, T.S. Horng, W.S. Chen, and C.H. Huang, Dual wideband printed monopole antenna for WLAN/WiMAX applications, IEEE Antennas Wireless 
PropagLett 6 (2007), 149-151.

[8]. J.Y. Wu, J.S. Row, and K.L. Wong, A compact dualband microstrip patch antenna suitable for DCS/GPS operations, Microwave Opt Techno Lett 29 (2001), 410-412.

[9]. J.I. Kim, B.M. Lee, Young Joong Yoon, Wideband printed dipole antenna for multiple wireless services, RAWCON 2001, IEEE Radio Wireless Conf 2001, pp. $153-156$.

[10].J.R. James and P.S. Hall, Handbook of microstrip antennas, Vol. I and II, Peter Peregrinus Ltd., London, 1989.

[11].G. Kumar and K.P. Ray, Broadband microstrip antennas, Artech House, Boston, 2003.

[12].K.L. Wong, Compact and broadband microstrip antennas, Wiley, New York.

\section{BIOGRAPHIES}

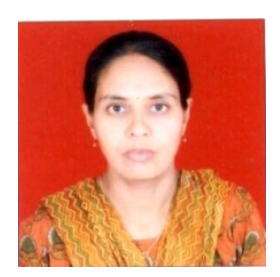

Rajeshwar Biradar received her M.Sc. degree in Department of Applied Electronics, from Gulbarga University, Gulbarga in the year 2002 and M. Phil degree from Vinayak Mission University, from Salem in the year 2007. Presently she is pursuing for $\mathrm{Ph}$. D degree under the guidance of Dr. S. N. Mulgi, Professor in the Department of P. G. Studies and Research in Applied Electronics, Gulbarga University, Kalaburgi, Her fields of interest include Microwave Electronics.

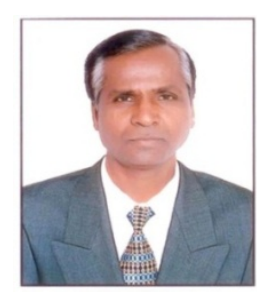

Dr. S. N. Mulgi received his M.Sc., M.Phil. and Ph.D. degrees in Applied Electronics, from Gulbarga University Gulbarga in the year 1986, 1989 and 2004 respectively. He is working as a Professor in Department of P. G. Studies and Research in Applied Electronics, Gulbarga University, Kalaburagi. He is an active researcher in the field of Microwave Electronics. He has published more than seventy five reputed peer reviewed International Journals and more than 30 in National Journals. He has presented several papers in International and National Conferences 